\title{
The Turnabout in the Insanity Defense
}

\section{ABSTRACT}

For over a century the dominant test of legal insanity in the United States was that set out by the English judges in Daniel M'Naghten's case in 1843 , under which it must be "clearly proved that, at the time of the committing of the act, the party accused was laboring under such a defect of reason, from disease of the mind, as not to know the nature and quality of the act he was doing; or if he did know it, that he did not know he was doing what was wrong." In the 1950 s, two competing formulas emerged: the "Durham" test-under which criminal conduct is excused when it is the "product" of mental disease or defect-and the American Law Institute's Model Penal Code. By the early 1980s, the Model Code formula, which excused a defendant if he lacked substantial capacity to control his own behavior, had been adopted in a majority of American jurisdictions. The case of John Hinckley, who attempted to assassinate President Reagan and who was acquitted on grounds of insanity, has precipitated calls for abolition or alteration of the insanity defense. The growing practice of deinstitutionalizing the mentally ill has cast doubt on the propriety of long term confinement of insanity acquittees. Several jurisdictions have adopted new approaches, including the defense of "guilty but insane." The major professional organizations-the American Psychiatric Association, the American Medical Association, and the American Bar Association-have repudiated the Model Penal Code approach. There is at present a near consensus that the insanity defense has become too broad and that it is a mistake to allow juries or expert witnesses to speculate about whether a defendant had free will at a given moment in the past. Medical and legal authorities are united in rejecting the notion of the previous generation of reformers that a broader insanity defense would make the criminal law more therapeutic and less punitive. Official positions adopted by the AMA, the ABA, and the APA signal these recent

Phillip E. Johnson is Professor of Law at the University of California, Berkeley.

Q 1985 by The Liniversity of Chicago. All rights reserved. 0-226-80800-9/85/0006-0006\$01.00 
developments and illuminate the major differences among the approaches currently under discussion.

For over a century, the dominant test of legal insanity in the United States was that set out by the English judges in Daniel M'Naghten's case in 1843. The "M'Naghten rule" or "right-wrong test" allowed the defense only where it could be "clearly proved that, at the time of the committing of the act, the party accused was laboring under such a defect of reason, from disease of the mind, as not to know the nature and quality of the act he was doing; or if he did know it, that he did not know he was doing what was wrong" (Weinreb 1980, p. 452). Some jurisdictions supplemented this concept of "knowledge of wrongfulness" with an additional "irresistible-impulse" test, which in extreme cases allowed the jury to acquit a defendant whose act resulted from a sudden and overpowering impulse (Weinreb 1980, pp. 459-60).

During the past twenty-five years, the insanity defense has been reshaped by the influential proposals of the American Law Institute's Model Penal Code $(1955,1962)$. The Code modified the traditional M'Naghten knowledge-of-wrongfulness test in a manner calculated to make it easier to demonstrate lack of criminal responsibility. There were two principal innovations. First, the new test excused anyone who lacked "substantial capacity to appreciate the criminality of his conduct." The purpose of using the terms "substantial capacity" and "appreciate" was to make it clear that a total lack of knowledge of the act's wrongfulness was not required, so that a defendant who "knew" only in some abstract sense that it was wrong to kill people or to steal might nonetheless be excused if his ability to understand or internalize that knowledge was seriously affected.

Second and more important, the Code introduced a volitional element to add to the solely cognitive test of the M'Naghten rule. The mentally ill defendant was to be excused, not only if he could not appreciate the criminality of his conduct, but also if he lacked "substantial capacity to conform his conduct to the requirements of law." The logic of excusing persons who cannot control their own conduct is straightforward: such persons ought not to be blamed, and in any event they cannot be deterred by the threat of punishment. If we assume that some criminal acts are directed by free will and others by psychological compulsion, and that juries guided by psychiatrists can accurately distinguish freely willed acts from psychologically compelled acts, then it follows that we should punish the former and not the latter. The Code's drafters felt that 
the irresistible-impulse test was an inept formulation of this principle, because its wording implied a limitation to "sudden, spontaneous acts as opposed to propulsions that are accompanied by brooding or reflection" (American Law Institute 1955, p. 157).

The history of the insanity defense after 1962 was the history of gradual adoption of the Model Penal Code's provision (commonly called the ALI [American Law Institute] test) in jurisdiction after jurisdiction. Even the United States Court of Appeals for the District of Columbia Circuit, which in 1954 had adopted the celebrated but unworkable "disease-product" rule that for a time seemed the wave of the future, acknowledged the superiority of the ALI formula in 1972 (United States v. Brawner, 471 F.2d 969 [D.C. Cir. 1972]). By 1982, every federal court of appeals and about half the states had adopted the ALI test. When the California supreme court belatedly adopted the ALI formulation in 1978, the court's opinion reflected an assumption that the step was nothing more than an acknowledgment of universally accepted scientific reality, much as if the court were to endorse the theory of relativity (People v. Drew, 22 Cal. 3d 333 [1978]). It seemed that the nearly impossible had been accomplished: a formulation of the insanity principle now existed that had the support of all except the most extreme determinists on one side and the most punitive reactionary elements on the other.

That complacency has been abruptly shattered. During 1982 and 1983, the American Psychiatric Association, the American Bar Association, and the American Medical Association announced official positions decisively repudiating the ALI test, and especially its crucial volitional element. The occasion for this shift of position was the notorious verdict in the case of John Hinckley, who wounded President Reagan and several other persons in an assassination attempt motivated by Hinckley's desire to impress a movie actress whom he had admired from a distance. Under federal law, the jury had to be instructed that they should acquit if there was a reasonable doubt about the defendant's sanity under the ALI test. If taken literally, that instruction amounted to a directed verdict of not guilty, given the fantastic motive and the fact that some distinguished psychiatrists had testified that Hinckley was insane. Frequently juries ignore the law in such cases and convict anyway, but the Hinckley jury surprised everyone by taking the instruction seriously and returning a not guilty verdict (Taylor 1982).

The resulting public outcry focused attention on the legal rules that 
seem to invite such a result. The Hinckley verdict was unquestionably the occasion for the reevaluation of the insanity defense by the major professional organizations, but it was no more the cause of their shift in position than the attack on Fort Sumter was the cause of the Civil War. Widespread intellectual discontent with psychiatric testimony and its accompanying ideology had existed well before the Hinckley case, and had already influenced a major law reform effort: the "deinstitutionalization" of the mentally ill.

Not very long ago, it was generally assumed that psychiatrists were capable of identifying dangerously mentally ill persons and predicting their future behavior. Society routinely locked such persons away in institutions until they should be "cured." Beginning in the 1960s, an unusual alliance of civil liberties lawyers, mental health professionals, and budget-cutting politicians cooperated to curtail drastically the practice of institutionalizing the mentally ill (Rhoden 1982). This change was made possible by a technological innovation: the development of new drug therapies that effectively control many of the destructive symptoms of mental illness. Deinstitutionalization also had its ideological side, however, and the ideology was one of pervasive distrust of psychiatric testimony. There was no lack of ammunition. Anyone with courtroom experience knows that psychiatric judgment is so extremely subjective that it is usually possible to retain a reputable psychiatrist to testify on either side of any controversial question. Diagnostic categories have changed enormously over the years, and on some topics (e.g., homosexuality) they have a political as well as a scientific dimension (Ennis and Littwack 1974).

The campaign to protect the liberties of the mentally ill particularly called into question the ability of psychiatrists to predict dangerous behavior. In this effect as in others, the opponents of psychiatric excess found that they had powerful allies within the psychiatric profession. Psychiatrists themselves were increasingly eager to disclaim omniscience. To their credit, genuine advances in knowledge inclined them to a greater humility in the face of what remained to be learned. Today, it is perfectly orthodox to say that psychiatrists have very little ability to predict behavior, and certainly their predictions are not sufficiently accurate to be relied upon as a justification for taking away a person's liberty (Diamond 1974).

There has been considerable difficulty over whether we can continue to justify routine confinement of the "criminally" insane in the light of the reforms in civil mental commitment law. Insanity acquittees are 
supposed to be not guilty, after all, and so they do not deserve to be punished. Furthermore, the verdict may mean only that there was a reasonable doubt as to the sanity of the accused at the time of the event, months or even years before the verdict. It would seem that a mental commitment order ought to be based on a determination that the former defendant is insane and dangerous at present, a conclusion that might be difficult to justify if we assume that there is no reliable method for determining dangerousness.

Judges have understandably been uncertain whether to accept a compelling line of argument that leads to outcomes-possibly including the outright release of such as John Hinckley - that society cannot accept. In People v. McQuillan, 392 Mich. 511, 221 N.W.2d 569 (1974), the supreme court of Michigan held that the State's insanity acquittees could be confined for evaluation only for sixty days, after which they were entitled to the same procedural protections as any other civilly committed patient. This decision led the Michigan legislature to pass the first law authorizing a verdict of "guilty but insane" (Stone 1982; see also Benbam v. Edwards, 678 F.2d 511 [5th Cir. 1982]).

On the other hand, the United States Supreme Court recently upheld the constitutionality of the provisions of the District of Columbia Code which provide for automatic, indefinite commitment of defendants found not guilty by reason of insanity, with subsequent release only for those who can prove by a preponderance of the evidence that they are no longer insane or dangerous (Jones v. United States, $103 \mathrm{~S}$. Ct. 3043 [1983]). The Supreme Court also held that the period of commitment was not limited by the maximum term of the criminal offense for which the accused might have been convicted. The Jones decision is highly questionable on its facts, since the only evidence of the acquittee's dangerousness was that he had committed an attempted petty theft, although he stipulated that he was insane at the time of the offense. It would be still more difficult for the courts to justify automatic commitment after a trial in which the acquittee had merely raised a reasonable doubt as to his sanity.

Although the customary practice of automatic commitment for insanity acquittees is not quite dead, its defenders are suffering from acute intellectual embarrassment. Dr. Alan Stone, a professor of law and psychiatry at Harvard University who was influential in formulating the American Psychiatric Association's statement on the insanity defense, commented that "the law created by the civil libertarians and the methods of treatment developed by psychiatrists now push in the 
same direction, and the traditional way of dealing with persons found not guilty by reason of insanity has been drastically transformed" (Stone 1982, p. 20).

The public reaction to the Hinckley verdict thus provided the occasion for a reevaluation of psychiatric defenses that was overdue and inevitable in any case. To guide the reader through the details of the three major reform proposals under consideration, following is an extremely condensed summary of each organization's institutional position:

1. The American Psychiatric Association's (APA) Statement on the Insanity Defense takes the position that the insanity defense should be retained but drastically narrowed. Because the criminal law presumes that punishment for wrongful deeds should be predicated on moral culpability, there must logically be a defense for defendants who do not possess free will and therefore cannot be said to have "chosen to do wrong" (APA 1982, p. 8). Although it assumes that lack of free will is the moral basis of the insanity defense, the APA nonetheless recommends eliminating the ALI test, with its controversial volitional element, in favor of a modernized wording of the M'Naghten formula drafted by Richard Bonnie (APA 1982, p. 12). This test excuses the defendant only if, as a result of mental disease or retardation, he was "unable to appreciate the wrongfulness of his conduct at the time of the offense." "Mental disease" is limited to conditions that "grossly and demonstrably impair a person's perception or understanding of reality": conditions such as "psychopathic personality disturbance" are emphatically excluded (APA 1982, p. 11).

Many lawyers and judges will be surprised to learn that psychiatrists no longer wish to testify as experts on the defendant's capacity to control his conduct and that they prefer a narrow definition of mental disease to an open-ended one. Expansion of the insanity defense in these respects was once thought to be necessary to permit psychiatrists to explain the defendant's condition without undue legalistic restrictions. Nonetheless, the APA Statement explains that psychiatric testimony about whether a defendant understood the wrongfulness of his act "is more reliable and has a stronger scientific basis" than does psychiatric testimony about whether a defendant could control his behavior. The APA acknowledges that "psychiatry is a deterministic discipline that views all human behavior as, to a good extent, 'caused.' " On the other hand, psychiatrists disagree about how this deterministic outlook should affect the moral and philosophical question of whether a 
person is responsible for his conduct. Expert psychiatric testimony about volition is therefore likely to be confusing to the jury (APA 1982, pp. 10-11).

The APA takes no position on whether the defense or prosecution should have the burden of proof, but does observe that psychiatric issues are usually not susceptible to proof "beyond a reasonable doubt." The APA does not oppose evidentiary rules that limit psychiatric testimony to description of the defendant's condition and bar any statement on the "ultimate issue" of sanity or insanity (APA 1982, pp. 1213).

Finally, the APA argues that it is a mistake to treat persons acquitted of violent crimes on the grounds of insanity as if they were equivalent to mentally ill persons who have not attacked anyone. They should be confined in a secure facility and the decision to release should be made by a group similar in composition to a parole board (APA 1982, pp. 1418). In other words, they should be treated much as they would be treated if they had been convicted. It is not clear that a defendant would receive any benefit from an acquittal under these circumstances, unless it be to escape a possible death sentence. Nonetheless, the APA Statement opposes allowing the jury to return a compromise verdict of "guilty but insane," on the ground that this too-easy alternative permits the jury to settle on a convenient label and thus avoid "grappling with the difficult moral issues inherent in adjudicating guilt or innocence," a task which serves an "important symbolic function" (APA 1982, p. 9).

2. The American Bar Association's (ABA) House of Delegates approved new standards for the insanity defense in February 1983. Like the APA, the ABA recommends dropping the volitional prong of the ALI test and excusing only persons who are "unable to appreciate the wrongfulness" of their criminal acts. The ABA does not limit the concept of mental disease to conditions producing a gross misperception of reality, however. Instead, it merely states that "mental disease or defect refers to impairments of mind, whether enduring or transitory, or to mental retardation which substantially affected the mental or emotional process of the defendant at the time of the alleged offense." The commentary states that this definition "attempts to clarify the meaning of the term 'mental disease or defect' " (ABA 1983, pp. 197-201). One wonders what the drafters would have written had their intent been to allow the term to remain obscure.

Otherwise, the ABA Standards provide that expert testimony about mental illness may be admissible where it is relevant to show that 
the defendant did not have the specific mental state required by the definition of the defense. (The APA did not address this question.) The defendant would be required to give advance notice of any defense based on mental condition and to submit to examination by courtappointed experts. The ABA would also restrict the psychiatrist from testifying on the ultimate issue of sanity and would place the burden of persuasion by a preponderance of the evidence on the prosecution. The ABA contemplates a civil commitment procedure following a verdict of not guilty by reason of insanity, but the sections of the Standards that deal with this subject have yet to be approved by the House of Delegates (ABA 1983, pp. 197-219).

3. The American Medical Association (AMA) approved a more radical change at its 1983 annual meeting. The AMA recommends that the defense of legal insanity be abolished outright and replaced by statutes providing for acquittal when a criminal defendant, as a result of mental disease or otherwise, lacks the state of mind or mens rea required as an element of the defense charged. Defendants found not guilty on this basis would be subject to civil commitment, with a presumption of continuing dangerousness for those acquitted of offenses involving violence. They would be released only on concurring medical certification and judicial determination that release poses no substantial public risk. Where mental illness does not serve as a defense (because it does not have the effect of causing the defendant to lack the culpability required by the definition of the offense), it could nonetheless be considered in mitigation of sentence (AMA 1983, p. 37).

The major disagreement, then, is that the organized medical profession wants to abolish the defense altogether, while the bar and psychiatric associations want to retain the defense but limit it fairly drastically. The AMA position explicitly endorses the reasoning of Norval Morris, whose book Madness and the Criminal Law (1982) argued for abolition of the special defense of legal insanity in favor of an approach directed solely to whether the defendant has satisfied the culpability requirements for the crime.

As applied to the Hinckley case, the AMA approach would mean that mental illness would be relevant only if it tended to show that Hinckley was incapable of forming an intent to kill anyone, which of course it would not. Hinckley's bizarre motive and history of irrational behavior would be considered only at sentencing, where such evidence might have a double effect. It would tend to lessen the defendant's blameworthiness, but at the same time it would tend to support confinement on 
the grounds of extraordinary dangerousness. Morris argues that psychiatric predictions of dangerousness are so fallible that courts should rarely rely on them as a basis for increasing a sentence (Morris 1982, pp. 171-72). Whether judges would respect that limitation in practice is doubtful.

The U.S. Department of Justice asked Congress to abolish the insanity defense during both the Nixon and Reagan administrations, although more recently it has supported the ABA-APA proposals to narrow the defense (Smith 1982). Now abolition has the support of the organized medical profession and one of our most prominent criminal justice scholars. The AMA report, relying heavily upon Morris, argues that it is arbitrary to single out mental illness from other factors that affect behavior. Why should mental illness be an excuse from criminal responsibility when "gross social adversity" (AMA 1983, pp. 30-31) is not? Morris wrote that because criminal behavior is less closely correlated with psychosis than with "being born to a one parent family living on welfare in a black inner-city area" (Morris 1982, pp. 62-63), it is irrational to allow a complete defense in one case and not the other (AMA 1983, pp. 30-31).

Moreover, according to Morris and the AMA Report, the special insanity defense does not even accomplish its stated purpose of shielding the mentally impaired from punishment. In practice it operates capriciously to exonerate a few mentally ill offenders who are either lucky or exceptionally well defended, while others with equally serious impairments go to prison. The AMA, quoting Morris, thus condemned the insanity defense as "an ornate rarity, a tribute to our capacity to pretend to a moral position while pursuing profoundly different practices" (AMA 1983, p. 30). This is a strong argument, particularly if one assumes that homicidal insanity acquittees are going to be locked away for at least as long as if they were convicted. How can the existence of such a defense be essential to the moral integrity of the criminal law if it makes so little tangible difference to the disposition of the offender?

Despite the strength of the argument, Morris's position is definitely a minority one among legal scholars. Most authorities would agree with the view of the APA and the ABA that recognition of an insanity defense is logically necessary to any criminal justice system based on a premise of moral accountability (Bonnie 1983). To understand the strength of this majority position, it is useful to compare the defense of insanity with the universally recognized and uncontroversial defense of infancy. The reason that we do not hold young children accountable 
under the criminal law is not that they are incapable of forming an intent. Even a dog knows the difference between being kicked and being stumbled over, and children know the difference between hurting other children accidentally and "on purpose." Although a child is capable of forming an intent, we do not consider small children to be sufficiently rational to hold them fully accountable for their behavior. Similarly, through the institution of the juvenile court we give adolescents something like a defense of "partial responsibility."

If this is uncontroversial with respect to actual children, then it ought to be equally acceptable when applied to the severely mentally retarded, and to psychotics who suffer a gross misperception of reality. The point is not that psychotics or the severely retarded are more likely than other people to commit crimes. On the contrary, it is probable that the more severely retarded or psychotic one is, the more likely it is that one will be incapable of complicated purposeful action of any kind, including criminal action. After all, six-year-old children hardly ever commit homicide, but when they do, they are excused. The insanity defense is a logical extension of the same principle. It divides those who are sufficiently rational to be held accountable for their actions from those who have not reached that level of understanding or maturity and perhaps never will (Johnson 1983).

The difference between children and psychotics, of course, is that psychotics are often extremely dangerous people, although it may be difficult to say exactly how dangerous a particular psychotic is. For this reason we confine psychotics who have committed violent acts, sometimes for a longer time than if they were found to be morally responsible. The AMA report cited this practice as evidence of social hypocrisy, and perhaps it is, but it is not illogical. The purpose of the insanity defense is not necessarily to benefit the insane offender, and it is certainly not to guarantee his liberty. On the contrary, a verdict of legal insanity (under a narrow definition such as that proposed by the APA) labels the individual as so thoroughly irrational that he cannot be trusted with liberty or expected to benefit from it. Perhaps the difference between convicting and committing a psychotic is largely a matter of symbolism (where the death penalty is not in the picture), but symbols are not necessarily unimportant.

An insanity defense of some kind therefore fits logically in a criminal justice system that holds most but not all human beings morally responsible for their actions. It does not follow, however, that we should 
have an insanity defense that is so broad as to exculpate persons whom the community considers morally responsible, regardless of whether a psychiatric diagnosis would appropriately include these persons within the category of the mentally ill. The ALI test contains the potential for extending the defense far beyond the limited number of persons whom the public does not in fact consider responsible for their actions. This is because the "substantial-capacity" test excuses persons who are not totally irrational, and especially because inability to control one's conduct is an open-ended, speculative concept. Our prisons are full of persons with damaged personalities and a long history of lack of success in controlling their impulses (Morris 1982).

The argument for adding a volitional element to the insanity defense was that it was thought to comport with the reality of mental illness, which may lead to a loss of behavioral control even where it does not affect the cognitive capacity to understand the wrongfulness of what one is doing (ALI 1955, p. 157). Progressive reformers in the early 1960 s were not worried that the jury would fall under undue influence from psychiatrists, or be hopelessly confused by professional debate over the validity of untestable deterministic theories of human behavior. They thought that the problem was rather how to open up the trial process so that jurors could fully understand what the psychiatrists wanted to tell them about the psychological causes of the defendant's behavior. As the psychiatrists became more knowledgeable about the real causes of criminal conduct, they would succeed in persuading ordinary persons sitting as jurors to accept their theories. If increasing psychiatric knowledge led to an increasing number of insanity acquittals, then this would be because the community, acting through the jurors, willed it to be so. Increasingly accurate psychiatric diagnosis would also lead to increasingly effective cures, and the public's safety would be far more efficaciously protected by humane treatment of the offender than by a brutal prison system which embitters its inmates (see, e.g., United States v. Wade, 426 U.S. 64, 66-67, 72 [9th Cir. 1970]).

The dramatic turnabout that has occurred on this issue is best illustrated by the 1982 APA statement. Although lawyers who endorsed the ALI test thought that they were thereby permitring psychiatrists to testify more realistically to what they knew about the human personality and the causes of criminal behavior, the official voice of psychiatry now suggests that with all good intentions the lawyers were leading 
psychiatry into a quagmire. The familiar "battle of the experts" in insanity trials has embarrassed the profession enormously by giving the impression that psychiatrists are quacks or worse. But it is the question that the law asks, rather than the answers that the experts give, that is to blame for the situation. No one knows whether a criminal who has committed a crime for some bizarre motive could have acted otherwise if he had wished to do so. All three organizations agree on this point. In the words of Richard Bonnie, quoted with approval in both the ABA and the AMA reports: "[E]xperience confirms that there still is no accurate scientific basis for measuring one's capacity for self-control or for calibrating the impairment of such capacity. There is, in short, no objective basis for distinguishing between offenders who were undeterrable and those who were merely undeterred, between the impulse that was irresistible and the impulse not resisted, or between substantial impairment of capacity and some lesser impairment" (ABA 1983, p. 199; AMA 1983, p. 10; Bonnie 1983, p. 196).

It would be wrong to emphasize the disagreement over whether or not to abolish the insanity defense when there is so much on which all three organizations agree. All agree that the present law ought to be drastically changed, and all agree on the direction that the change ought to take. It is likely that Congress will legislate for the first time on this subject in the near future, and its task will be greatly assisted by the degree of consensus that exists among the three major professional organizations and the Department of Justice.

First, there is a general agreement that it is a mistake to allow either the jury or the expert witnesses to speculate about whether a particular defendant had free will at a particular moment in the past. In retrospect, it seems difficult to understand why the reformers of the previous generation were so confident that psychiatric testimony on this subject would be enlightening to the jury rather than confusing and contradictory. Perhaps the best explanation is that the reformers thought that no harm would be done by erroneous insanity acquittals, because confinement in a mental institution would adequately protect the security of the public and at the same time provide much more humane treatment to the offender than a term in prison. From this perspective, what needed to be done was to provide for as many insanity acquittals as public opinion would allow, the jury being seen as a surrogate for public opinion.

The reaction to the Hinckley verdict plainly belied the notion that the 
public regards the jury, particularly a jury subject to manipulation by lawyers and confused by incomprehensible legal standards, as an adequate safeguard for the public interest. It is also now clear that the psychiatric profession itself shares to some degree the general public's skepticism about the objectivity of psychiatric knowledge. Indeed, the APA Statement is so emphatic in denying that psychiatrists are experts about whether a particular individual had control over his behavior or not that the statement could be used in court to challenge the qualifications of a psychiatric expert even in the absence of any change in the law. If the organization best qualified to speak for the psychiatric profession considers free will to be a legal and moral concept whose existence cannot be proved or disproved by psychiatric methods, then no individual psychiatrist should be permitted to mislead a jury by offering "expert" testimony on this subject. Where a witness does so testify, the Statement should provide material for effective cross examination (see Johnson 1983).

The second major point of agreement is that persons found not guilty of a crime solely because of their mental illness should not be released outright but should be subject to civil commitment to protect the safety of the public. The Statement asserts that the dangerousness of insanity acquittees who have perpetrated violent acts can be assumed from the nature of those acts, without relying on psychiatric predictions. Release of violent mentally ill persons should be at the discretion of "an experienced body that is not naive about the nature of violent behavior committed by mental patients and that allows a quasi-criminal approach for managing such persons" (APA 1982, p. 17). In short, where confinement of the mentally ill beyond a reasonable period for treatment is necessary to protect the public safety or to satisfy public opinion, the psychiatrists would rather not be responsible for managing the institutions or setting the release date. The AMA report also contemplates civil commitment for defendants acquitted because a mental impairment prevented them from forming the required intent or mens rea. In such cases, the AMA recommends that there should be a "presumption of continuing dangerousness with respect to those acquitted of offenses involving violence." Release from custody "should be based on concurring medical certification and judicial determination that release poses no substantial public risk" (AMA 1983, p. 37). Probably the ABA position will be similar to the others, when the details of the civil commitment procedures have been officially approved. 
It seems to be generally agreed that the difficulties of predicting dangerous conduct do not require that we release defendants who are found not morally responsible for violent actions solely because of their mental impairment. The APA and the AMA both reject the notion, popular with some lawyers and judges, that it is unfair to treat persons who have been found not guilty of a violent crime on insanity grounds differently from persons who have never attacked anyone. In fact, if we wish to preserve the liberties of mentally ill persons who do not commit serious criminal acts, it is essential to treat insanity acquittees as a separate legal category. The inevitable consequence of treating both groups alike is that society will demand broad civil commitment authority for all persons who are mentally ill, so it can be sure that homicidal psychotics will not be at liberty. The "criminally insane" ought to be treated separately from the harmlessly mentally ill, and the difference in treatment should be based on the actual commission of violent acts rather than on psychiatric prediction.

The difference between substantially narrowing the insanity defense and eliminating it altogether may not be very great in practical terms. Cases like Hinckley, where batteries of psychiatrists testify against each other in an all-out adversary battle, are the exception rather than the rule. Many insanity verdicts are by stipulation, with all parties agreed that a commitment for psychiatric treatment is a more appropriate disposition than a prison sentence. Presumably, some means would be found to divert most of these defendants from the criminal process even if they no longer had a defense. On the other hand, it is difficult to imagine that the prosecution would lose many contested insanity cases if the defense were limited to those defendants unable to understand the wrongfulness of their conduct, if the burden of proof were placed on the defense, and if psychiatrists were prevented from testifying about the ultimate issue of sanity. Under either proposal, few mental illness defenses would succeed in contested cases, and a successful defense would result in a civil commitment process fully adequate to protect the public interest. That this is the outcome desired by the leading professional organizations concerned with mental health is a striking change from the optimism and idealism of past years. We used to think that advancing psychiatric knowledge would make criminal punishment seem primitive and ineffective as a means of combating crime. Instead, we have learned how far we are from any ability to understand the mysteries of human freedom, evil, and moral responsibility. 


\section{Postscript}

The reforms discussed in this article came to pass while this volume was in press. On October 14, 1984, President Reagan signed the Comprehensive Crime Control Act of 1984, containing the "Insanity Defense Reform Act of 1984." This Act (codified as 18 U.S.C.A. § 20) narrows the insanity defense in federal criminal cases to situations where the defendant "as a result of a severe mental disease or defect, was unable to appreciate the nature and quality or the wrongfulness of his acts" at the time of the offense. The statute also provides that the defendant has the burden of proving his insanity by clear and convincing evidence, and there are stringent civil commitment proceedings for persons found not guilty by reason of insanity.

\section{REFERENCES}

American Bar Association. 1983. Report on Standards for Criminal Justice: Nonresponsibility for Crime. Chicago: American Bar Association.

American Law Institute. 1955. Model Penal Code. Tentative Draft no. 4. Philadelphia: American Law Institute.

- 1962. Model Penal Code. Proposed Official Draft. Philadelphia: American Law Institute.

American Medical Association. 1983. Report of the Board of Trustees: The Insanity Defense in Criminal Trials and Limitation of Psychiatric Testimony. Chicago: American Medical Association.

American Psychiatric Association. 1982. Statement on the Insanity Defense. Washington, D.C.: American Psychiatric Association.

Bonnie, Richard J. 1982. A Model Statute on the Insanity Defense. Charlotresville: University of Virginia, Institute of Law, Psychiatry and Public Policy.

- 1983. "The Moral Basis of the Insanity Defense." American Bar Association Journal $69: 194-97$.

Diamond, Bernard L. 1974. "The Psychiatric Prediction of Dangerousness." University of Pennsy/vania Law Review 123:439-52.

Ennis, Bruce J., and Thomas R. Littwack. 1974. "Psychiatry and the Presumption of Expertise: Flipping Coins in the Courtroom." California Law Review 62:693-752.

Johnson, Phillip E. 1983. "Book Review." University of Chicago Law Review 50:1534-49.

Morris, Norval. 1982. Madness and the Criminal Law. Chicago: University of Chicago Press.

Rhoden, Nancy K. 1982. "The Limits of Liberty: Deinstitutionalization, Homelessness, and Libertarian Theory." Emory Law Journal 31:375-440.

Smith, William French. 1982. "Limiting the Insanity Defense: A Rational Approach to Irrational Crimes." University of Missouri Law Review 47:605-19. 
Stone, Alan. 1982. “The Insanity Defense on Trial." Harvard Law Scbool Bulletin 34(1):15-21.

Taylor, Stuart. 1982. "Too Much Justice." Harper's (September 1982), pp. 5664.

Weinreb, Lloyd L. 1980. Criminal Law: Cases, Comment, Questions. Mineola, N.Y.: Foundation Press. 